\title{
Fuzzy Inference System Tsukamoto Penentuan Nilai Reward yang Diterima Karyawan
}

\author{
Fuzzy Inference System of Tsukamoto is used to \\ Determine the Reward Value Received by Employees \\ Yogi Primadasa*1, Alfiarini ${ }^{2}$ \\ 1,2 Sistem Informasi STMIK Bina Nusantara Jaya Lubuklinggau \\ E-mail:*1yogiak45@gmail.com, ${ }^{2}$ alfiaini3@gmail.com
}

\begin{abstract}
Abstrak
Karyawan sangat berperan penting terhadap kesuksesan sebuah lembaga, sehingga dalam pemberian reward, perguruan tinggi harus mempertimbangkan kriteria yang dibutuhkan. Untuk pemberian reward yang pantas, lembaga melakukan seleksi untuk kandidat karyawan. Permasalahan timbul dikarenakan banyak faktor lain yang mempengaruhi sistem penerimaan reward. Dalam pemberian reward terkadang tidak objektif dalam penentuan nilai-nilai yang menjadi kriteria. Oleh karena itu, dibuatkan suatu sistem pendukung keputusan, yang nantinya dapat membatu dalam pengambilan keputusan terkait nilai-nilai yang menjadi kriteria yang menjadi aspek pendukung. Sistem ini didukung dengan Fuzzy Inference System menggunakan metode Tsukamoto yang dibuat berdasarkan norma-norma sumber daya manusia dengan kriteria-kriteria yang telah ditentukan. Parameter yang dijadikan kriteria pemberian reward karyawan ada 3 yaitu Kinerja, Kedispilinan dan Kemampuan karyawan. Untuk mecari nilai keangotaannya masing - masing variabel akan menggunakan kurva linier. Nilai Keanggotaan ini kemudian dicari nilai fire strength dan nilai bobotnya untuk kemudian dicari nilai Z rata-rata terbobot. Nilai Z rata-rata terbobot inilah yang dijadikan acuan dalam menentukan reward.
\end{abstract}

Kata Kunci - Reward, Fuzzy Inference System, Metode Tsukamoto, Karyawan

\begin{abstract}
Employees are very instrumental to the success of the college, so in the reward system, universities must consider the necessary criteria. For the provision of appropriate reward, the college undertook the selection of candidates for the employees. Problems arise due to manyother factors that affect the reward system acceptance. In the reward system is sometimes not objective in determining the values of the criteria. Therefore, made a decision support system, which can later be petrified in decision making related to values that becomes the criteria on the ancillary aspects. The system is supported by the Fuzzy Inference System using methods Tsukamoto made based on the norms of human resources with the criteria that have been determined. Parameters used as criteria for granting rewards employees there are three, namely performance, disciplinary and capability of employees. To look for value groups each - each variable will be using a linear curve. This membership value then find the value of fire strength and weight values to then find the $Z$ value weighted average. $Z$ value weighted average is used as a reference in determining the reward.
\end{abstract}

Keywords — Fuzzy Inference System, Method Tsukamoto, Employee 


\section{PENDAHULUAN}

Dalam rangka memberikan motivasi kepada karyawan yang berhubungan erat dengan tugas dan tanggung jawab mereka yang terkait langsung dengan pencapaian sasaran, sebuah lembaga mengadakan program pemberian reward. Kegiatan ini dilakukan untuk memberikan motivasi kepada karyawan yang memiliki kualitas kinerja kerja yang terus memuaskan, memiliki kedispilinan yang baik, dan kemampuan yang meningkat. Tujuan dilakukan proses pemilihan pemberian reward terhadap karyawan yang berkualitas adalah sebagai tanda ucapan terima kasih Pimpinan terhadap kinerja karyawantersebut. Selain itu kegiatan pemberian reward ini dilakukan agar kinerja karyawan terus dapat meningkat dan dapat mempertahankannya, sehingga dapat memacu pegawai lain yang belum mendapat reward atas prestasi kerjanya. Reward pada umumnya adalah pemberian penghargaan kepadaseseorang atas sesuatuyang telah dihasilkan [1].

Dalam proses pemilihan pemberian reward kepada karyawan, ada beberpa kendala yang dihadapi diantaranya kesulitan dalam memilih karyawan-karyawan yang layak mendapatkan reward dengan adanya beberapa kriteria sebagai penilaian. Untuk membantu pihak lembaga dalam mengambil keputusan karyawan yang berhak mendapatkan reward diperlukan suatu sistem pendukung keputusan. DSS sendiri merupakan sistem informasi interaktif yang menyediakan pemodelan, dan pemanipulasian data untuk membatu pengambilan keputusan dalam situasi yang semiterstruktur dan sistuasi yang tidak terstruktur, dimana tak seorang pun tahu secara pasti bagaimana keputusan seharusnya dibuat [2].

Penelitian sebelumnya, pemberian rewardpernah dilakukan oleh Didie Nanda Pribadi [3] dengan menggunakan metode perbandingan Eksponensial. Metode perbandingan Eksponensial merupakan salah satu metode yang digunakan untuk melakukan pengukuran kinerja karyawan yang selanjutnya karyawan yang telah terpilih akan diberikan bonus utama, karena pada metode ini dapat menentukan urutan prioritas alternatif-alternatif keputusan dengan kriteria jamak.

Penelitian sebelumnya, model fuzzy Tsukamoto pernah dilakukan oleh Achmad Zaki [4] untuk mengklasifikasi dalam prediksi krisis energi di Indonesia. Sistem Inferensi Fuzzy dengan metode tsukamoto mampu mengklasifikasi masalah krisis energi seperti minyak bumi, gas alam dan batubara terhadap parameter produksi, konsumsi, GDP dan penduduk.

Sistem pendukung keputusan ini menggunakan metode Tsukamoto dengan menerapkan parameter atau variabel data pendukung yang meliputi Kinerja, Kedisiplinan dan Kemampuan yang menjadi kriteria dalam penilaian. Pada metode Tsukamoto setiap rule diterapkan menggunakan himpunan-himpunan fuzzy dengan fungsi keanggotaan yang konstan, Fuzzy Tsukamoto adalah metode yang memiliki toleransi pada data dan sangat fleksibel. Kelebihan dari metode Tsukamoto yaitu bersifat intuitif dan dapat memberikan tanggapan berdasarkan informasi yang bersifat kualitatif, tidak akurat, dan ambigu (Nadia Roosmalita Sari, 2015) [5].

Diharapkan dengan penelitian ini, pemberian reward menggunakan fuzzy Tsukamoto dapat menghasilkan output yang sesuai dengan keadaan atau kriteria yang ada sehingga reward dapat diberikan kepada karyawan secara objektif.

\section{METODE PENELITIAN}

\subsection{Penjelasan Tentang Fuzzy}

Teori fuzzy merupkan logika tegas, yang memiliki nilai benar atau salah. Dalam teori logika fuzzy sebuah nilai dianggap benar dan salah secara bersamaan, tergantung pada nilai keanggotaanya [6]. Ada beberapa alasan mengapa menggunakan logika fuzzy:

1. Fuzzy logic naturalness pendekatannya dalam memecahkan masalah.

2. Dapat di bangun dan dikembangkan dengan mudah

3. Ketidakpresisian terhadap data dapat di toleril

4. Hubungan data input output dari sembarang sistem mudah untuk dilakukan 
5. Untuk membangun fuzzy logic pengetahuan atau pengalaman dari pakar dapat dipakai tanpa proses pelatihan

6. Secara konvensional fuzzy logic dapat bekerjasama dengan teknik-teknik kendali.

7. Bahasa alami atau bahasa manusia adalah dasar fuzzy logic.

\subsection{Himpunan Fuzzy}

Pada himpunan fuzzy nilai keanggotaan antara 0 dan 1 . Apabila x memiliki nilai 0 berarti $\mathrm{x}$ tidak menjadi anggota himpunan $\mathrm{A}$, demikian pula apabila $\mathrm{x}$ memiliki nilai 1 berarti x menjadi anggota penuh pada himpunan A [7]. Misalkan variabel kinerja didalam penelitian ini dibagi menjadi 2 kategori yaitu:

MEMUASKAN puas $\geq 10$ atau $\leq 20$

MENGECEWAKAN kecewa $\leq 10$

Dari kategori diatas dapat dijelaskan bahawa:

1. Apabila seorang karyawan memiliki nilai 15 , maka dia dikatakan MEMUASKAN $((15)=1)$

2. Apabila seorang karyawan memiliki nilai 9, maka dia dikatakan MENGECEWAKAN $((9)=0)$

\subsection{Fungsi Keanggotaan}

Fungsi keanggotaan merupakan kurva yang menjelaskan bagaimana masing-masing titik dalam ruang input dikelompokan ke dalam nilai keanggotaan antara 0 dan 1, apabila x memiliki nilai 0 berarti $\mathrm{x}$ tidak menjadi anggota himpunan $\mathrm{A}$, demikian pula apabila $\mathrm{x}$ memiliki nilai 1 berarti x menjadi anggota penuh pada himpunan A [7]. Fungsi keanggotaan bilangan $\mu(x)$, yang menentukan derajat keanggotaan dari elemen dalam himpunan fuzzy A [8]. Penelitian ini hanya menggunakan kurva linier untuk menghitung derajat keanggotaanya. Fungsi keanggotaanya linier pada penelitian ini terbagi menjadi 2 himpunan, fungsi keanggotaan himpunan linier naik dan turun [4].

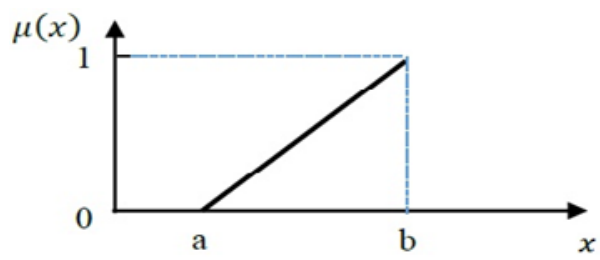

Gambar 1. Fungsi Keanggotaan Himpunan Linier Naik

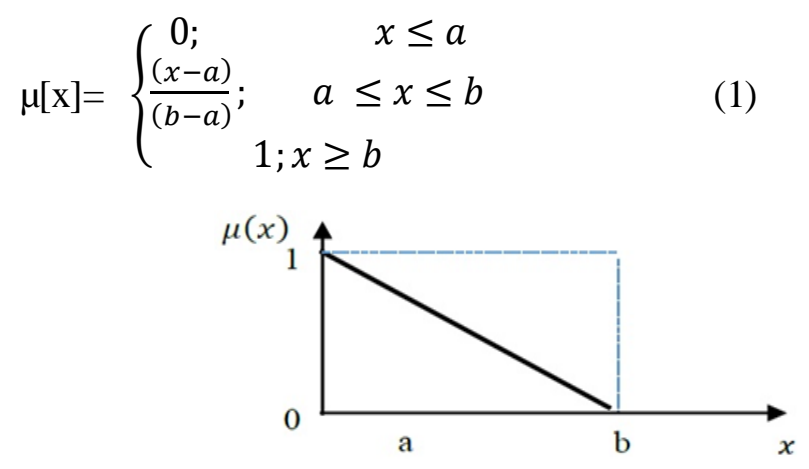



Gambar 2. Fungsi Keanggotaan Himpunan Linier Turun

$$
\mu[\mathrm{x}]=\left\{\begin{array}{c}
1 ; \\
\frac{(b-x)}{(b-a)} ; \quad \quad \quad a \leq x \leq b \\
0 ; x \geq b
\end{array}\right.
$$




\subsection{Inferensi Fuzzy}

Hasil inferensi dari tiap-tiap aturan diberikan secara tegas berdasarkan a-predikat (fire strength). Hasil akhirnya diperoleh dengan menggunakan rata-rata terbobot [8]. Inferensi Fuzzy menggunakan metode Tsukamoto dapat dilihat pada Gambar 3.

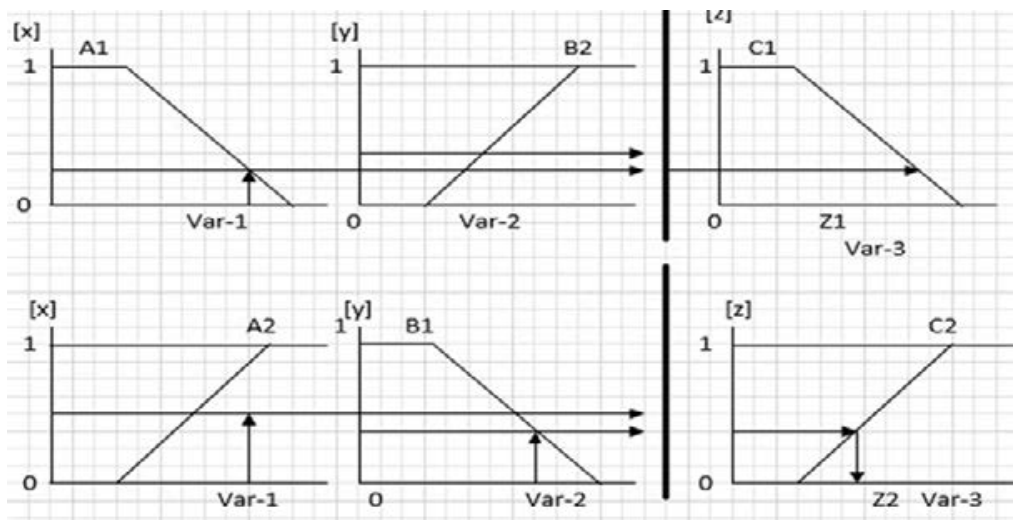

Gambar 3. Inferensi dengan menggunakan Metode Tsukamoto

Dari gambar inferensi menggunakan metode Tsukamoto, diperoleh nilai rata-rata terbobot, nilai rata-rata terbobot dapat dicari dengan rumus di bawah ini[8]:

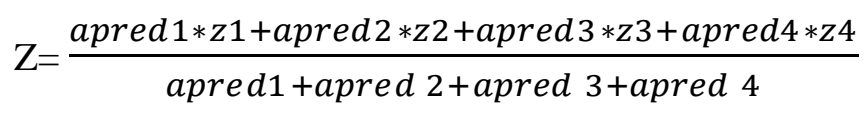

\section{HASIL DAN PEMBAHASAN}

Pada proses penelitian ini kriteria kelayakan untuk pemberian reward direpresentasikan sebagai variabel input. Sedangkan variabel output pada proses ini berupa reward.

a. Variabel Input

Variabel input yang digunakan dalam penelitian ini adalah kriteria kelayakan yang memiliki nilai yang mendukung. Dalam kasus ini ada 3 variabel untuk kriteria, yaitu kriteria Kinerja, Kedisipilinan dan Kemampuan.

b. Variabel Ouput

Variabel ouput dalam penelitian ini berupa reward yang mana hasil reward didapatkan dari variabel input berupa kriteria yang ditentukan.

\subsection{Fuzzy Inference System Rule}

Hasil dari proses perhitungan nilai keanggotaan fuzzy kemudian dinferensikan terhadap aturan-aturan fuzzy (rules) [5]. Terdapat 3 variabel input (t) yang perlu diimplementasikan terhadap fuzzy rules. Dalam menentukan reward yang diberikan, ada 8 aturan yang digunakan yaitu:

[R1] IF Kinerja mengecewakan AND Kedisiplinan buruk AND Kemampuan menurun THEN Reward tidak dapat.

[R2] IF Kinerja mengecewakan AND Kedisiplinan buruk AND Kemampuan meningkat THEN Reward tidak dapat.

[R3] IF Kinerja mengecewakan AND Kedisiplinan baik AND Kemampuan menurun THEN Rewardtidak dapat.

[R4] IF Kinerja mengecewakan AND Kedisiplinan baik AND Kemampuan meningkat THEN Rewarddi pertimbangkan. 
[R5] IF Kinerja memuaskan AND Kedisiplinan buruk AND Kemampuan menurun THEN Reward tidak dapat.

[R6] IF Kinerja memuaskan AND Kedisiplinan baik AND Kemampuan menurun THEN Rewarddi pertimbangkan.

[R7] IF Kinerja memuaskan AND Kedisiplinan buruk AND Kemampuan meningkat THEN Reward di pertimbangkan.

[R8] IF Kinerja memuaskan AND Kedisiplinan baik AND Kemampuan meningkat THEN Reward dapat.

\subsection{Fungsi Keanggotaaan Variabel}

Pada penelitian ini variabel dibagi menjadi 2, variabel input dan variabel ouput. Variabel input terdiri dari variabel Kinerja, Kedisiplinan dan Kemampuan, sedangkan variabel output berupa reward. Berikut fungsi keanggotaan variabel input dan output:

1. Variabel Kinerja

Variabel Kinerja terdiri dari 2 himpunan fuzzy yaitu MENGECEWAKAN dan MEMUASKAN, dengan fungsi keanggotaan seperti pada Gambar 4.



Gambar 4. Fungsi Keanggotaan Variabel Kinerja

2. Variabel Kedisiplinan

Variabel Kedisiplinan terdiri dari 2 himpunan fuzzy yaitu BURUK dan BAIK, dengan fungsi keanggotaan seperti pada Gambar 5.



Gambar 5. Fungsi Keanggotaan Variabel Kedisiplinan 
Citec Journal, Vol. 4, No. 2, Februari 2017 - April 2017

3. Variabel Kemampuan

Variabel Kemampuan tediri dari 2 himpunan fuzzy yaitu MENURUN dan MENINGKAT, dengan fungsi keanggotaan seperti pada Gambar 6.

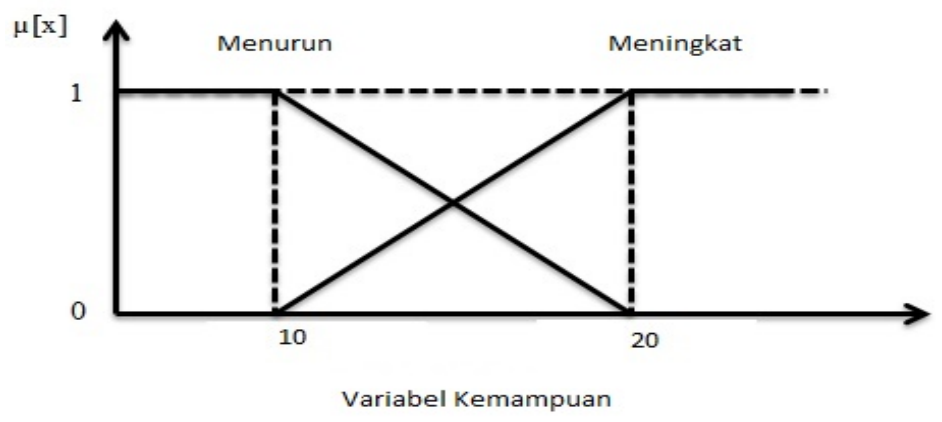

Gambar 6. Fungsi Keanggottan Variabel Kemampuan

4. Variabel Reward

Variabel Reward terdiri dari 3 himpunan fuzzy yaitu TIDAK DAPAT, DI PERTIMBANGKAN dan DAPAT, dengan fungsi keanggotaan seperti pada Gambar 7.

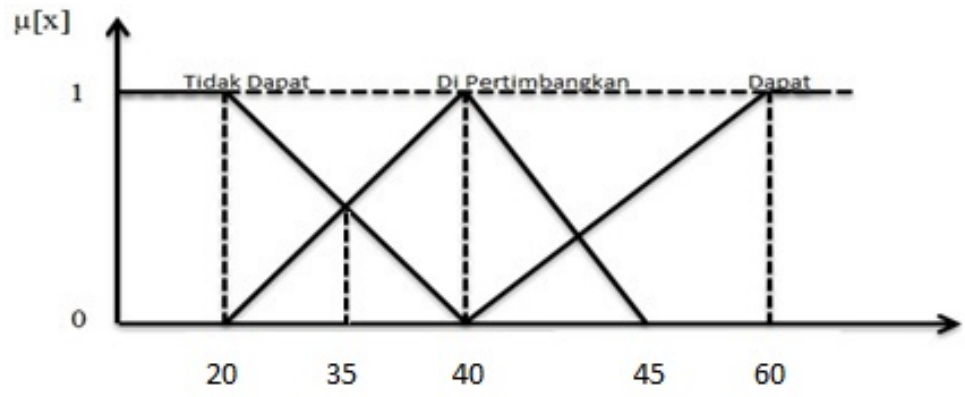

Gambar 7. Fungsi Keanggotaan Variabel Reward

\subsection{Studi Kasus}

Penelitian ini menggunakan beberapa data karyawan STMIK BINA NUSANTARA JAYA Lubukinggau sebagai data inputan pada setiap kriteria. Data karyawan dapat di lihat pada Tabel 1.

Tabel 1. Contoh Data Karyawan

\begin{tabular}{|c|c|c|c|}
\hline Kriteria & Kinerja & Kedisplinan & Kemampuan \\
\hline Alternatif & 16 & 15 & 17 \\
\hline A & 18 & 18 & 19 \\
\hline B & 14 & 19 & 12 \\
\hline C & 13 & 13 & 12 \\
\hline D & \multicolumn{2}{|c}{} \\
\hline
\end{tabular}

1. Variabel kinerja untuk alternatif A

Variabel kinerja memiliki 2 himpunan fuzzy yaitu MENGECEWAKAN dan MEMUASKAN

$$
\begin{aligned}
& \mu \text { MEMUASKAN }[\mathrm{x}]=\left\{\begin{array}{cc}
0 ; & x \leq 10 \\
\frac{(x-10)}{(10)} ; & 10 \leq x \leq 20 \\
1 ; x \geq 20
\end{array}\right. \\
& \mu \text { MEMUASKAN }[16]=(16-10) / 10 \\
& =0,6
\end{aligned}
$$




$$
\begin{aligned}
& \mu \text { MENGECEWAKAN }[\mathrm{x}]=\left\{\begin{array}{cc}
1 ; & x \leq 10 \\
\frac{(20-x)}{(10)} ; & 10 \leq x \leq 20 \\
0 ; & x \geq 20
\end{array}\right. \\
& \begin{array}{l}
\mu \text { MENGECEWAKAN }[16]=(20-16) / 10 \\
=0,4
\end{array}
\end{aligned}
$$

2. Variabel kedisiplinan untuk alternatif $A$

Variabel kedisiplinan memiliki 2 himpunan fuzzy yaitu BAIK dan BURUK

$$
\begin{aligned}
& \mu \mathrm{BAIK}[\mathrm{x}]=\left\{\begin{array}{cc}
0 ; & x \leq 10 \\
\frac{(x-10)}{(10)} ; & 10 \leq x \leq 20 \\
1 ; x \geq 20
\end{array}\right. \\
& \mu \mathrm{BAIIK}[15] \quad=(15-10) / 10 \\
& =0,5 \\
& \mu \mathrm{BURRUK}[\mathrm{x}]=\left\{\begin{array}{cc}
1 ; & x \leq 10 \\
\frac{(20-x)}{(10)} ; & 10 \leq x \leq 20 \\
0 ; & x \geq 20
\end{array}\right. \\
& \begin{array}{l}
\mu B \text { BURUK[15] }=0,5 \\
=0,5) / 10
\end{array}
\end{aligned}
$$

3. Variabel kemampuan untuk alternatif A

Variabel kemampuan memiliki 2 himpunan fuzzy yaitu MENINGKAT DAN MENURUN

$$
\begin{aligned}
& \mu \text { MENINGKAT }[\mathrm{x}]=\left\{\begin{array}{cc}
0 ; & x \leq 10 \\
\frac{(x-10)}{(10)} ; & 10 \leq x \leq 20 \\
1 ; & x \geq 20
\end{array}\right. \\
& \mu \text { MENINGKAT[17] }=(17-10) / 10 \\
& =0,7 \\
& \mu \operatorname{MENURUN}[\mathrm{x}]=\left\{\begin{array}{cc}
1 ; & x \leq 10 \\
\frac{(20-x)}{(10)} ; & 10 \leq x \leq 20 \\
0 ; & x \geq 20
\end{array}\right. \\
& \mu \text { MENURUN[17] }=(20-17) / 10 \\
& =0,3
\end{aligned}
$$

4. Variabel Reward

$$
\begin{aligned}
& \mu \text { Tidak Dapat }[\mathrm{x}] \quad=\left\{\begin{array}{cc}
1 ; & x \leq 20 \\
\frac{(40-x)}{(20)} ; & 20 \leq x \leq 40 \\
0 ; & x \geq 40
\end{array}\right. \\
& \mu \text { Di Pertimbangkan[x] }=\left\{\begin{array}{cc}
0 & x \leq \text { atau } x \geq 60 \\
\frac{(x-20)}{(20)} & 20 \leq x \leq 60 \\
\frac{(50-x)}{10} & x \geq 60 \\
1 ; & x
\end{array}\right. \\
& \mu \text { Dapat }[\mathrm{x}] \quad=\left\{\begin{array}{cc}
0 ; & x \leq 50 \\
\frac{(x-50)}{(10)} ; & 50 \leq x \leq 60 \\
1 ; & x \geq 60
\end{array}\right.
\end{aligned}
$$


Citec Journal, Vol. 4, No. 2, Februari 2017 - April 2017

Setelah semua variabel diperoleh nilainya, selanjutnya mencari nilai z untuk setiap aturan.

[R1] IF Kinerja mengecewakan AND Kedisiplinan buruk AND Kemampuan menurun THEN Reward tidak dapat

a-predikat1 $=\mu$ kinerja mengecewakan $\cap \mu$ kedisiplinan buruk $\cap \mu$ kemampuan menurun

$=\min (0,4 ; 0,5 ; 0,3)$

$=\min 0,3$

Himpunan Reward Tidak Dapat

$$
\mathrm{z1} \quad \begin{aligned}
= & (40-\mathrm{z}) / 20=0,3 \\
& =40-(0,3 * 20)=34 \\
& =34
\end{aligned}
$$

[R2] IF Kinerja mengecewakan AND Kedisiplinan buruk AND Kemampuan meningkat THEN Reward tidak dapat

a-predikat2 $=\mu$ kinerja mengecewakan $\cap \mu$ kedisplinan buruk $\cap \mu$ kemampuan meningkat

$=\min (0,4 ; 0,5 ; 0,7)$

$=\min 0,4$

Himpuna Reward Tidak Dapat

$$
\text { z2 } \quad \begin{aligned}
&=(40-\mathrm{z}) / 20=0,4 \\
&=40-(0,4 * 20)=32 \\
&=32
\end{aligned}
$$

[R3] IF Kinerja mengecewakan AND Kedisiplinan baik AND Kemampuan menurun THEN Reward tidak dapat

a-predikat $\quad=\mu$ kinerja mengecewakan $\cap \mu$ kedisiplinan baik $\cap \mu$ kemampuan menurun

$$
\begin{aligned}
& =\min (0,4 ; 0,5 ; 0,3) \\
& =\min 0,3
\end{aligned}
$$

Himpunan Reward Tidak Dapat

$$
\mathrm{z3} \quad \begin{aligned}
= & (40-\mathrm{z}) / 20=0,3 \\
& =40-(0,3 * 20)=34 \\
& =34
\end{aligned}
$$

[R4] IF Kinerja mengecewakan AND Kedisiplinan baik AND Kemampuan meningkat THEN Reward dipertimbangkan

$a$-predikat $\quad=\mu$ kinerja mengecewakan $\cap \mu$ kedisiplinan baik $\cap \mu$ kemampuan meningkat

$$
=\min (0,4 ; 0,5 ; 0,7)
$$$$
=\min 0,4
$$

Himpunan Reward di pertimbangkan

$$
\begin{aligned}
\mathrm{z}_{41} & =(\mathrm{z}-20) / 20 \quad=0,4 \\
& =20+(0,4 * 20)=28 \\
& =28 \\
\mathrm{z}_{42} \quad & =(50-\mathrm{z}) / 10=0,4 \\
& =50-(0,4 * 20)=42 \\
& =42
\end{aligned}
$$

Maka nilai $\mathrm{z}_{4}=(28+42) / 2=35$ 
[R5] IF Kinerja memuaskan AND Kedisiplinan buruk AND Kemampuan menurun THEN Reward tidak dapat

$a$-predikat $\quad=\mu$ kinerja memuaskan $\cap \mu$ kedisiplinan buruk $\cap \mu$ kemampuan menurun $=\min (0,6 ; 0,5 ; 0,3)$

$=\min 0,5$

Himpunan Reward Dapat

$$
\begin{aligned}
\mathrm{z}_{5} & =(40-\mathrm{z}) / 20=0,3 \\
& =40-(0,3 * 20)=34 \\
& =34
\end{aligned}
$$

[R6] IF Kinerja memuaskan AND Kedisiplinan baik AND Kemampuan menurun THEN Reward di pertimbangkan

$a$-predikat $\quad=\mu$ kinerja memuaskan $\cap \mu$ kedisiplinan baik $\cap \mu$ kemampuan menurun

$$
\begin{aligned}
& =\min (0,6 ; 0,5 ; 0,3) \\
& =\min 0,3
\end{aligned}
$$

Himpunan Reward di pertimbangkan

$$
\begin{aligned}
\mathrm{z}_{61} & =(\mathrm{z}-20) / 20 \quad=0,3 \\
& =20+(0,3 * 20)=26 \\
& =28
\end{aligned}
$$

$$
\begin{aligned}
\mathrm{z}_{62} & =(50-\mathrm{z}) / 10=0,3 \\
& =50-(0,3 * 20)=44 \\
& =44
\end{aligned}
$$

Maka nilai $\mathrm{z}_{6}=(26+44) / 2=35$

[R7] IF Kinerja memuaskan AND Kedisiplinan buruk AND Kemampuan meningkat THEN Reward di pertimbangkan

$a$-predikat $\quad=\mu$ kinerja memuaskan $\cap \mu$ kedisiplinan buruk $\cap \mu$ kemampuan meningkat

$$
\begin{aligned}
& =\min (0,6 ; 0,5 ; 0,7) \\
& =\min 0,5
\end{aligned}
$$

Himpunan Reward di pertimbangkan

$$
\begin{aligned}
\mathrm{z}_{71} & =(\mathrm{z}-20) / 20 \quad=0,5 \\
& =20+(0,5 * 20)=30 \\
& =28 \\
\mathrm{z}_{72} & =(50-\mathrm{z}) / 10=0,5 \\
& =50-(0,5 * 20)=40 \\
& =44
\end{aligned}
$$

Maka nilai $\mathrm{z}_{6}=(30+40) / 2=35$

[R8] IF Kinerja memuaskan AND Kedisiplinan baik AND Kemampuan meningkat THEN Rewarddapat

$a$-predikat $\quad=\mu$ kinerja memuaskan $\cap \mu$ kedisiplinan baik $\cap \mu$ kemampuan meningkat $=\min (0,6 ; 0,5 ; 0,7)$

$$
=\min 0,5
$$

Himpunan Reward Dapat

$$
\begin{aligned}
\mathrm{z}_{8} & =(\mathrm{x}-50) / 10=0,5 \\
& =50+(0,5 * 10)=55 \\
& =55
\end{aligned}
$$


Citec Journal, Vol. 4, No. 2, Februari 2017 - April 2017

Setelah nilai z setiap himpunan didapatkan, maka dari sini kita dapat mencari berapakah nilai $\mathrm{z}$, rumus nilai $\mathrm{z}$ adalah:

$$
\begin{gathered}
\mathrm{Z}=\frac{\text { apred } 1 * \mathrm{Z} 1+\text { apred } 2 * \mathrm{Z} 2+\text { apred } 3 * \mathrm{Z} 3+\text { apred } 4 * \mathrm{z} 4+\text { apred } 5 * z 5+\text { apred } 6 * z 6+\text { apred } 7+z 7+\text { apred } 8+z 8}{\text { apred } 1+\text { apred } 2+\text { apred } 3+\text { apred } 4+\text { apred } 5+\text { apred } 6+\text { apred } 7+\text { apred } 8} \\
\mathrm{Z}=\frac{0,3 * 34+0,4 * 32+0,3 * 34+0,4 * 35+0,3 * 34+0,3 * 35+0,5 * 35+0,5 * 55}{0,3+0,4+0,3+0,4+0,3+0,3+0,5+0,5}=\frac{112,9}{3}=37,6
\end{gathered}
$$

Jadi jumlah nilai reward untuk karyawan tersebut adalah 37,6 bearti reward hasilnya Dipe rtimbangkan

Hasil dari keseluruhan perhitungan nilai reward, masing-masing alternatif dapat dilihat pada Tabel 2.

Tabel 2. Hasil Keseluruhan pernitungan nilai Reward

\begin{tabular}{|c|c|c|c|c|l|}
\hline Alternatif Kriteria & \multirow{2}{*}{ Kinerja } & Kedisplinan & Kemampuan & Nilai & \multirow{2}{*}{ Hasil } \\
\hline A & 16 & 15 & 17 & 37,6 & Dipertimbangkan \\
\hline B & 18 & 18 & 19 & 45,9 & Dapat \\
\hline C & 14 & 19 & 12 & 35,05 & Dipertimbangkan \\
\hline D & 13 & 13 & 12 & 33,7 & Tidak Dapat \\
\hline
\end{tabular}

\section{KESIMPULAN}

Berdasarkan pembahasan di atas yang telah di paparkan maka peneliti mengambil kesimpulan sebagai berikut:

1. Metode Tsukamoto dapat melakukan perhitungan nilai rewarduntuk karyawan sesuai dengan kriteria-kriteria yang ditentukan.

2. Output yang dihasilkan adalah hasil nilai karyawan dan apakah karyawan tersebut mendapatkan reward, atau di pertimbangkan dan atau tidak dapat.

\section{SARAN}

Penelitian ini menggunakan salah satu data karyawan sebagai data contoh, untuk mendapatkan nilai reward. Untuk penelitian lebih lanjut, peneliti akan menggunakan seluruh data karyawan STMIK BINA NUSANTARA JAYA Lubuklinggau untuk mengetahui keakuratan metode Tsukamoto dalam pengambilan keputusan penentuan nilai reward setelah menggunakan data tersebut.

\section{DAFTAR PUSTAKA}

[1] Puspitasari, R., 2015, Pengaruh Pemberian Hadiah (Reward) Terhadap Kemandirian Belajar Anak di TK Tunas Muda Karas Kabupaten Magetan TA 2015/2016, Prosiding Seminar Nasional Pendidikan "Meretas Sukses Publikasi Ilmiah Bidang Pendidikan Jurnal Bereputasi”, Surakarta, 21 November 2015.

[2] Kusrini, 2007, Konsep dan Aplikasi Sistem Pendukung Keputusan. Yogyakarta, Andi Offset.

[3] Pribadi, D. N., 2014, Sistem Pendukung Keputusan Pemberian Reward Kepada Karyawan Menggunakan Metode Perbandingan Eksponensial (Studi Kasus: PT HD Finance, Surabaya) 
[4] Zaki, A., Santoso, H. A., 2016, Model Fuzzy Tsukamoto untuk Klasifikasi dalam Predisksi Krisis Energi di Indonesia, Citec Journal, No 3, Vol 3, hal 185-199.

[5] Sari, N. R., Mahmudy, W. F., 2015, Fuzzy Inference System Tsukamoto Untuk Menentukan Kelayakan Calon Pegawai, Seminar Nasional Sistem Informasi Indonesia, Surabaya, 2-3 November.

[6] Wiguna, R. Y., Haryanto, H., 2015, Sistem Berbasis Aturan Menggunakan Logika Fuzzy Tsukamoto Untuk Prediksi Jumlah Produksi Roti Pada CV.Gendis Bakery. Skripsi. Fakultas Ilmu Komputer, Universitas Dian Nuswantoro, Semarang.

[7] Maryaningsih, Siswanto, Mesterjon, 2013, Metode Logika Fuzzy Tsukamoto Dalam Sistem Pengambilan Keputusan Penerimaan Beasiswa, Jurnal Media Infotama, Vol 9, No 1, Hal 140165.

[8] Sri,Kusumadewi, 2003, Artificial Integellince (Teknik dan Aplikasinya).Yogyakarta. Graha Ilmu. 